\title{
CONDICIONAMIENTOS INTERNOS EN LA VARIACIÓN DE LOS PRONOMBRES PERSONALES ÁTONOS EN LOS HECHOS DE DON MIGUEL LUCAS DE IRANZO ${ }^{1}$
}

\author{
FRANCISCO DÍAZ MONTESINOS \\ JuAN ANDRÉS VILLENA PONSODA \\ Universidad de Málaga
}

\section{INTRODUCCIÓN}

\section{Objetivo}

El objetivo de este trabajo es analizar los condicionamientos linguísticos internos en el uso de los pronombres personales átonos de tercera persona $(l o(s), l a(s), l e(s))$ en el castellano medieval del siglo Xv, tal y como se presenta en el texto de la Relación de los hechos del muy magnifico e más virtuoso señor, el señor don Miguel Lucas, muy digno condestable de Castilla. Los materiales están extraídos del manuscrito 2092 de la Biblioteca Nacional. Este códice está fechado en el siglo XV -mientras que los otros manuscritos completos conservados son de siglos posteriores- y deriva directamente del manuscrito original ${ }^{2}$.

\footnotetext{
1 El presente trabajo se ha realizado gracias a la ayuda de la Consejería de Educación de ia Junta de Andalucia (HUM-392). Agradecemos a Manuel Almeida (Universidad de La Laguna) su generosa lectura critica y exhaustiva de versiones previas de este trabajo.

${ }^{2}$ La edición paleográfica de este códice ocupa las páginas 59-846 del trabajo de F. Díaz Montesinos, Léxico de los Hechos del condestable Miguel Lucas de Iranzo (3 vols.), Madrid, Editorial de la Universidad Complutense de Madrid, 1985. Sobre la descripción de los manuscritos, véase la misma obra, páginas 38-54 y las páginas XII-XIV y XXV-LXXvIII de J. Cuevas Mata, J. del Arco Moya, José del Arco Moya, Relación de los hechos del muy magnífico e más virtuoso señor, el señor don Miguel Lucas, muy digno condestable de Castilla, Jaén, Universidad, 2001. Sobre el autor y la fecha de composición, véase Díaz Montesinos, Ibid., págs. 3-38 y Cuevas Mata et alii, ibid., XVIII-XXXIV, así como Catherine Soriano del Castillo, Los hechos del Condestable Miguel Lucas de Iranzo, Estudio y edición (2 vols.), Madrid, Editorial de la Universidad Complutense, 1993.
}

RFE, LXXXIV, $2004,1 \stackrel{\circ}{\circ}^{\circ}$ págs. $95-127$ 
La idea es que los factores lingüísticos internos (gramaticales, textuales y léxicos) pueden servir para explicar una parte importante de la variación en un corpus de datos homogéneo con respecto a la variación social o estilística. En la lengua hablada la influencia de los condicionamientos extemos (sociales, estilísticos, geográficos) en la explicación de estas variables se ha estudiado en interacción con la de los factores intemos, de modo que el conocimiento de la mencionada influencia en una etapa de la evolución de la lengua puede contribuir a aclarar algunos aspectos todavía oscuros.

En el texto de referencia, los rasgos inherentes del antecedente, y en particular si su referente no es una persona, hacen prácticamente categorico el funcionamiento del llamado sistema etimológico. La variación se da en el sentido de una marcada inclinación hacia el denominado sistema referencial, con una notable tendencia a la invasión por parte de le/les de las funciones de acusativo/objeto directo con antecedente de persona, en la línea de la orientación 'genérica' de muchas áreas del español. Los factores gramaticales (como el género, el número o el tipo de construcción sintáctica), léxicos (como el origen etimológico) o textuales (como la posición del clítico) interaccionan y permiten reconstruir el entomo linguístico básico en el que el leísmo pudo iniciarse en las áreas de funcionamiento del sistema pronominal etimologico.

Para el análisis cuantitativo de los datos hemos considerado - una vez establecido el hecho de que la variación solo se produce en los casos con antecedente personal - que el uso de le/es frente a lo/os y la/las es una opción que la estructura de la lengua ofrece a los hablantes, de modo que constituye un proceso que puede ser objeto de un análisis variable condicionado por varios factores ${ }^{3}$. El análisis multivariable de regresión logística es el más adecuado, puesto que: 1) permite trabajar con variables dependientes e independientes nominales como las que se manejan aquí; 2) hace posible comparar el efecto independiente de múltiples factores sobre el proceso de elección variable y seleccionar la mejor combinación de estos. Para la realización del mencionado análisis se ha utilizado el programa Goldvarb 2.0 para ordenadores McIntosh ${ }^{4}$ perteneciente a la serie Varbrul, que se basa en los modelos de análisis de regla variable 5 .

\footnotetext{
${ }^{3}$ David Sankoff, "Variable rules», Sociolinguistics. An international handbook of the science of language and society, U. Ammon, N. Dittmar, K. Mattheier (eds.), Berlín-Nueva York, Walter de Gnyyter, 1988, págs. 984-997.

${ }^{4}$ David Rand, David Sankoff, Goldvarb 2.0. A Variable Rule application for the McIntosh, Montreal, Centre de Recherches Mathématiques, 1990.

${ }^{5}$ Cfr. Henrietta Cedergren, David Sankoff, «Variable rules: performance as a statistical reflection of competence», Language 50, 1974, págs. 333-355; D. Sankoff, «Variable rules», loc. cit.; David Sankoff, Pascale Rousseau, «Advances in Variable Rule methodology", Lan guage variation. Models and methods, Sankoff, David (ed.), Nueva York, Academic Press, 1978, págs. 57-69.
} 


\section{Sistema etimológico y sistema referencial}

Dentro de la tradición gramatical española, la variación (y la evolución histórica) en el uso de los pronombres átonos de tercera persona se ha explicado mediante el cruce de dos tendencias que actuarían conjunta y contradictoriamente ${ }^{6}$ : por un lado, la tendencia a eliminar las distinciones de caso a favor de las de género $\mathrm{y}$, por otro, la tendencia a distinguir los entes personales de los no-personales. A partir del análisis de la lengua hablada, diversos autores han elaborado otras interpretaciones del fenómeno relacionadas con variables geográficas y sociales ${ }^{7}$. Fernández-Ordónez propone la necesidad de distinguir - junto a las alteraciones del uso pronominal relacionadas con el adstrato- el letsmo de las áreas en las que rige el sistema etimológico del uso pronominal basado en el sistema referencial. En el sistema etimológico la elección del pronombre responde a la función sintáctica y' al número y, si la función es OBJETO-ACUSATIVo, también al género. En el sistema referencial se desatienden las distinciones funcionales de caso para establecer la referencia atendiendo, pri-

6 Rufino José Cuervo, eLos casos enclíticos y proclíticos del pronombre de tercera persona en castellano», Romania 24, 1895, págs. 95-113 y 219-263; M.* Teresa Echenique Elizondo, «El sistema referencial en español antiguo», RFE 61, 1981, págs. 113-157; Salvador Fernández Ramírez, Gramática española. 3.2. El pronombre (volumen preparado por José Polo), Madrid, Arco/Libros, 1987 [1951]; «Ün proceso lingüístico en marcha», Presente y futuro de la lengua española II, Madrid: OFINES, 1964, págs. 277-285; Rafael Lapesa, «Sobre los orígenes y evolución del leísmo, laísmo y lósmo», Festschrift Walter von Warburg, Kart Baldinger (ed.), Tubinga, Max Niemeyer, 1968, págs. 523-551; Francisco Marcos Marn, Estudios sobre el pronombre, Madrid, Gredos, 1978; M.* Jesús López Bobo, «Sobre el léísmo en el Libro de Buen Amor», Verba 17, 1990, págs. 343-361; Antonio Quilis, M. Cantarero, M. J. Albalá, R. Guerra, Los pronombres le, la, lo y sus plurales en la lengua expañola hablada en Madrid, Madrid, CSIC, 1985.

7 Erica García, The Role of Theory in Linguistic Analysis. The Spanish Pronoun System, Amsterdam, North-Holland Linguistic Series 19, 1975 (cfr. Pélix Monge, «Notas a una hipótesis sobre el leísmo», Serta Philologica Femando Lázaro Carreter I, Madrid, Cátedra, 1983, págs. 441-453); Francisco García González, (1978): «El letsmo en Santander», Estudios ofrecidos a Emilio Alarcos Llorach III, Oviedo, Universidad, 1978, págs. 87-101; «Los pronombres personales en el oriente de Asturias", Estudios y trabayos del Seminariu de lingua asturiana II, Oviedo, Universidá đ'Uvieu, 1979, págs. 47-56; $*$ le $(l u)$, la, lo $(l u) /$ en el Centro-Norte de la Penfnsula», Verba 8, 1981, págs. 347-353; Inés Femández-Ordóñez, «Leísmo, lásmo y lósmo: estado de la cuestión», Los pronombres átonos, $\mathrm{O}$. Fernández Soriano (ed.), Madrid, Taurus, 1993, págs. 63-69; «Isoglosas internas del castellano. El sistema referencial del pronombre átono de tercera persona», $R F E$ 74, 1994, págs. 71-125; «Leísmo, lásmo y loísmo», Gramática descriptiva de la lengua española, vol. I, Ignacio Bosque, Violeta Demonte (eds.), Madrid, Espasa Calpe, 1999, págs. 1317-1397; Flora Klein-Andreu, «Factores sociales en algunas diferencias lingiústicas en Castilla la Vieja», Papers, Revista de Sociología 11, 1979, págs. 46-67; «Distintos sistemas de empleo de le, la, lo. Perspectiva sincrónica, diacronica y sociolingüístican, Thesaurus 36, 1981, págs. 284-304; «Variación actual y reinterpretación histórica: lefs, la/s, lo/s en Castillan, Estudios de variación sintáctica, Serrano, Mara José (ed), Madrid-Francfort, Iberoamericana-Vervuert, 1999, págs. 197-220. 
mero, a la categorización del antecedente en continuo o discontinuo, y en segundo lugar, si es discontinuo, al género y al número.

La posible relevancia de diferencias de género y de los rasgos 'continuo / discontinuo' o 'persona / no persona' resulta relativamente fácil de establecer atendiendo a los rasgos inherentes o al género gramatical del antecedente, si bien hay que tener en cuenta los casos de discordancia ("concordancia ad sensum') y las recategorizaciones de distinta índole (personificación de objetos, por ejemplo) ${ }^{8}$. Como se dijo arriba, en nuestro documento tenemos variación en los clíticos con antecedente de persona, especialmente en singular y de género masculino.

La función sintáctica, en cambio, resulta más difícil de establecer. Puesto que se trata de una cuestión crucial, debemos utilizar un criterio objetivo y transparente cuando se trata de decidir si hay o no leísmo; esto es, cuál es el caso o la función en tal construcción cuyo núcleo es tal verbo y, en consecuencia, cuál es la forma esperada del pronombre personal. Los procedimientos a nuestro alcance son dos:

1. Criterio etimologico.-En este primer procedimiento se toman como base las construcciones latinas. En este caso, se observan los cambios de interpretación sintáctica de las funciones del latín al español. Los ejemplos 1-4 se construyen en latín en acusativo, pero en el romance español son dativos:

1. [como] su alteza le amava y quería [...], al marqués y maestre pesándoles d'ello e aviendo çelos e inbidia, siempre le tratavan quanto mal pudieron $(218 \mathrm{r} 22)$

2. para que a todas e qualesquier personas del obispado de Jahen que quisiesen aprender les abezase Gramática y Retorica (316r 14)

3. [a los moros] preguntóles que qué les paresçía la caballería de la çibdad de Jahen (79r 8)

4. vino al señor condestable y rogóle muy mucho que non quisiese fazer aquella partida (20r 20) (cfr. depués que muchas vezes sobr'ello fue requerido y rogado, 6vose de llegar a la tregua (205r 17)).

${ }^{8}$ Gente y dinero son sustantivos continuos (Ignacio Bosque, «El nombre común», Gramática descriptiva de la lengua española (3 tomos), Ignacio Bosque, Violeta Demonte (eds.), Madrid, Espasa Calpe, 1999, págs. 3-75: 8 y ss.) femenino y masculino, respectivamente, pero en los ejemplos siguientes (i-iii) el pronombre responde a lo designado por tales vocablos:

i) Y muchas vezes su alteza, los ojos llenos de agua, mirava a la gente e les dizía que por su lealtad [...] les entendía fazer muchas merçedes (279r 1 y 2 )

ii) [...] quedó tan gastada la gente, que fue maravilla entre tantos peligros y angustias poderlos detener y no desamparar la çibdad (328r 16)

iii) $Y$ commo quiera qu'el dicho don Alonso acometió muchas vezes de mandar dar dinero al dicho comendador de Montizón, para pagar la dicha gente que allí tenía, nunca jamás los quiso resçebir [...] salvo toda estovo a costa e sueldo del dicho señor condestable (286r 26). 
Como se comprueba, a un acusativo latino (miseret me alicuius rei, docet pueros grammaticam) le corresponde una forma de dativo en castellano, dativo que, además, es el caso que se selecciona en las áreas en las que se distinguen los casos.

2. Criterio funcional. El segundo procedimiento consiste en partir de las estructuras sintácticas españolas actuales. El problema, por lo tanto, reside en saber cuál es la función sintáctica de los clíticos personales. Dicha función no resulta siempre clara, por ej., en los segmentos subrayados en los ejemplos 5-13:

5. [antecedente: la fortaleza de Montizón] ya otras vezes su señoría $\underline{\underline{l} a}$ mandó socorrer y basteçer (250v 26)

6. E commo de dentro estava asaz gente por temor del dicho señor condestable, que siempre d' él se temían, socorrieron $q$ las puertas (68r 2)

7. en socorrer aquella fortaleza en que tantas dubdas avía no consistra la salvación de la vida y estado de su alteza (253v 25)

8. E que estos entrados, luego el dicho obispo vernía a $\operatorname{los} s$ socorrer con más gente $(85 r 28)$

9. Y todavía él y el dicho Salvador peleavan muy bien con los dichos moros, fasta qu' el dicho comendador e otros quatro de cavallo que venían con él les socorrieron (250r 21) (Cfr. el señor rey y todos los otros cavalleros [...] se vieron en asaz peligro, salvo porque fueron socorridos de la gente del real $(12 \mathrm{r} 14)$

10. "Señor, mirad y fablad esta gente que tan lealmente vos ha servido" (278r 19)

11. con grande reverencia volvió a fablar al señor rey (140 16)

12. E luego vido a la señora condesa e a doña Guiomar [...], las quales le fizieron reverençia, e él las fabló con grande amor (278v 18)

13. estando el palaçio lleno de gente, la señora doña Guiomar les fabló desde una ventana (171r 22).

El canon de referencia a partir del cual podemos juzgar un cambio en el uso del pronombre esperado varía en función de cómo se interprete la construcción (leísmo aparente) o de las diferentes normas o modelos ideales regionales (leísmo de variación dialectal).

\section{HIPÓTESIS}

\section{El leísmo de persona}

La teórica regularidad etimológica por la cual la función de objeto directo (OD) se realiza mediante los clíticos LO/S, LA/S y la función de objeto indirecto (OND) mediante $\mathrm{LE} / \mathrm{S}$ se altera de modo unilateral, esto es, utilizándose las formas etimológicas de dativo LE/S para realizar funciones gramaticales de 
acusativo (leísmo), pero no a la inversa. Este fenómeno ( $O D \rightarrow L B / S$ ) se produce en nuestro texto únicamente con antecedente personal (leísmo de persona) y, desde luego, no es categórico, de modo que estamos ante un hecho genérico de variación (OD $\rightarrow \mathrm{LE} / \mathrm{S}$, LA/S, LO/S) del que la aparición de $\mathrm{LE} / \mathrm{S}$ es una especie o variante (junto con $\mathrm{LA} / \mathrm{S}$ y LO/S) cuya frecuencia relativa es necesario considerar. De este modo, los objetos directos (OD) se expresan a través de las formas pronominales de acusativo (A) o, en menor medida, de dativo (D), en tanto que los objetos indirectos (OIND) se realizan mediante las formas de dativo (D) exclusivamente:

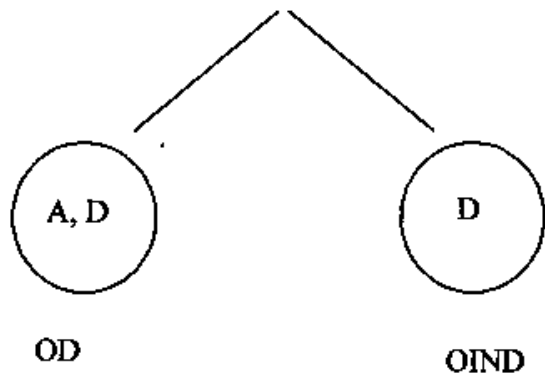

Este leismo personal en función de OD ocurre solo en un subgrupo de los casos virtuales de A; es decir, entornos en los que se espera la aparición de formas etimológicas en acusativo en función de un análisis sintáctico objetivo. Son aquellos casos cuya definición sintáctica o funcional no es clara, en el sentido de que la estructura o el significado oracional en el que aparecen admiten más de una interpretación (estructuras diádicas, verbos polisémicos ${ }^{9}$, etc.). En consecuencia, se trata mayoritariamente de casos que tuvieron, han tenido o tienen vacilaciones ${ }^{10}$. Por lo tanto, dado el carácter unilateral del leismo, los casos que interesan aquí son únicamente los correspondientes a la función de objeto directo (OD), de modo que se excluyen del análisis los de objeto indirecto (OND). En dicho subconjunto de casos ocurre, así pues, la variación estudiada aquí. Los verbos y construcciones con alternativas en el sentido expresado arriba son susceptibles de incluir leísmo personal $(\mathrm{LO} / \mathrm{s}, \mathrm{LA} / \mathrm{s} \rightarrow l e / s)$, en tanto que en aquellos casos ajenos a dichas alternativas la frecuencia es considerablemente menor.

${ }^{9}$ Véase Félix Monge, «A proposito de le y lo», Romania ingeniosa. Festschrift fïr Dr. Gerold Hilty, Ludf́, G. et alii (eds.), Benna-Frankfurt-Nueva York-París, Peter Lang, 1987, páginas 347-363.

${ }^{10}$ Fernández-Ordónez, «Leístnon, loc. cit., págs. 1323-1341. 
Así pues, en el subconjunto considerado (OD) nos encontramos con casos claros de acusativo (A) y con otros menos claros (A/D):

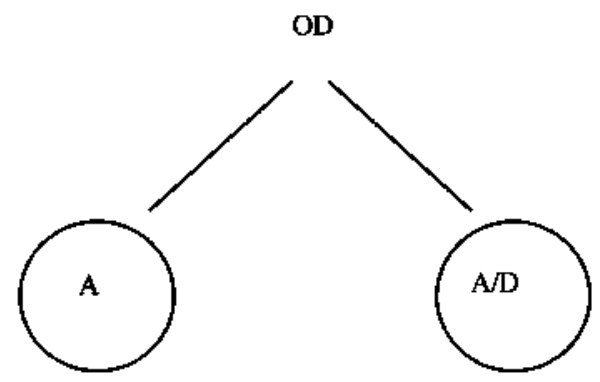

Los casos incluidos en A no presentarían leísmo (te lo/la presento) o lo harian solo irregularmente, en tanto que entre los incluidos en A/D el fenómeno se daría de forma prácticamente categórica (le felicito). Una forma de entender esto consiste en suponer que el oD se realiza mediante formas de A $(l o / s, l a / s)$ y de $\mathrm{D}(l e / s)$ como subconjuntos separados, tal y como se hizo antes:

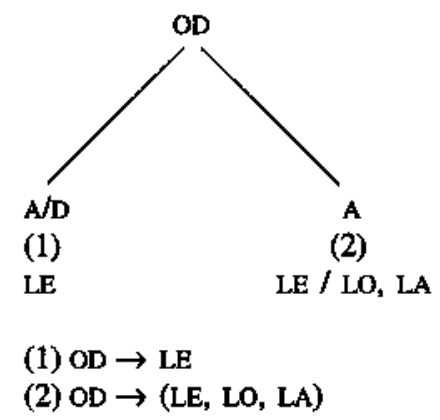

Lo más frecuente es la realización de oD mediante formas de A $(l o / s, l a / s)$ en el segundo grupo y, a la inversa, mediante formas de D $(l e / s)$ en el primer grupo. Ahora bien, cuando se usa $l e / s$ para oD se suspende una diferencia semántica que funciona en el sistema etimológico:

i) $L E / S$ 'afectación indirecta de la acción', ' $\alpha$ masc.', ' $\alpha$ plu.'

ii) $L O / S$ 'afectación directa de la acción', 'masc.', ' $\alpha$, plu.'

iii) LA/S 'afectación directa de la acción', 'fern.', ' $\alpha$ plu.'.

11 Juan Andrés Villena Ponsoda, «Fundamentos semánticos de la variación lingǘrstica», $A c$ tas del VIll Simposio de la Asociación de Profesores de Español «Elio Antonio de Nebrija», Málaga, Diputación Provincial, 2003, págs. 121-146. 
Esta suspensión de las diferencias entre formas diferentes ${ }^{11}$ permite que estas se utilicen como variantes de una misma variable subyacente $(O D \rightarrow L E$, LO, LA). La diferencia entre (1) y (2), arriba, está en que, en el primer caso (AD) la suspensión de dichas diferencias semánticas es constante y casi categórica, en tanto que, en el segundo caso (A), el proceso no está tan avanzado, de modo que, parcialmente, las mencionadas diferencias siguen existiendo.

Planteado así el problema, la cuestión está en cómo se delimitan ambos subconjuntos de casos y si la repartición se debe al azar o bien si está condicionada por factores gramaticales, textuales y léxicos, como se anotó con anterioridad.

\section{Variable dependiente}

Como se deduce de lo expuesto hasta aquí, tenemos importantes problemas cuando tratamos de definir la variable lingíística o género del que las variantes han de ser consideradas especies: (V) $\rightarrow / x, y /$. Como se dijo arriba, partimos de la base de que, en las condiciones restrictivas específicas en las que se produce variación en el uso de los clíticos personales dentro de las áreas en las que domina el sistema etimológico (antecedente personal, OD), las variantes LE/S, LO/S, LA/S constituyen un conjunto de equivalencia en el sentido de que realizan o cumplen una misma función o significado gramatical, en la medida en que - como se explic6 arriba- se han suspendido o neutralizado en ese contexto las diferencias denotativas que las diferencian ${ }^{12}$. Ahora bien, $i$ cuál es Ia variable que las abarca en las condiciones especificadas? ¿Podemos hablar de una variable (LO/S y, resp., LA/s) como prototípica de la función oD o del caso ACUS e interpretar los usos de LE/S como desviaciones de la etimología y por tanto como ejemplos de la tendencia al cambio en el sentido del sistema referencial? ¿Es necesaria tal identificación?

La consideración de los ejemplos aducidos arriba ( $\$ 0.2)$ indica que:

i) Establecer la mencionada identificación sería inadecuado, puesto que las vacilaciones se dan tanto en el castellano medieval como en el español moderno.

ii) Basar la construcción de la variable únicamente en la etimología latina sería unilateral, puesto que se han producido cambios en la evolución diacrónica desde el latin hasta el castellano medieval y el español modemo. Esto nos hace pensar asimismo en el carácter circular de la argumentación, puesto que si no están claros los criterios de definición de las funciones o si estas dependen

12 Villena, «Fundamentos semánticos», loc. cit. 
fuertemente de las interpretaciones (llámense normas, modelos ideales, etc.), tampoco disponemos de un punto de partida objetivo.

Ante estas dificultades, hemos optado por establecer las funciones $(O D \cong$ ACUSATIVO, OIND $\equiv$ DATIVO) a partir del número de participantes en el proceso referido por el verbo, teniendo en cuenta solo las denominadas funciones centrales (SUJ, OBJ DIRECTO, OBJ INDIRECTO), sean o no valenciales ${ }^{13}$. En el caso de las estructuras triactanciales (SU, OD, OND), el uso actual de las formas pronominales de acusativo y de dativo resulta predecible y uniforme en el sistema etimológico, sea cual sea el origen latino. En las estructuras biactanciales, por el contrario, en el uso actual se ha de distinguir entre $v+$ OIND (<DATIVo o ACUSATIVO) y $\mathrm{V}+$ OD (< ACUSATIVo o DATIVO). En OIND se han incluido todos aquellos casos en los que en el español actual se construye con dativo ${ }^{14}$. Bajo oD se han agrupado todos los usos en los que se presenta bien el acusativo, o bien alternancia entre las formas de acusativo y las de dativo en las áreas actuales distinguidoras de caso, alternancia que ya se daba en latín ${ }^{15}$. $\mathrm{La}$ construcción latina con dativo o con acusativo, a su vez, se tendrá en cuenta en la variable denominada 'etimología'.

La consecuencia es que restringimos el corpus de casos para el análisis multifactorial a las ocurrencias de clíticos en la función de $\mathrm{OD} \cong \mathrm{ACUS}$ en estructuras biactanciales, puesto que ni en las estructuras triactanciales ni en la función de $\mathrm{OIND} \equiv$ DAT se producen alternancias. Lo que interesa ahora es saber qué factores y en qué medida influyen en la alternancia de los clíticos en el mencionado entorno.

\section{Proposiciones}

1. El sistema etimológico funciona regular y categoricamente en las estructuras oracionales con clíticos en función de oND, que presentan sin excepción formas en dativo (D).

${ }^{13}$ José M." García-Miguel, «La duplicación de complemento directo e indirecto como concordancian, Verba 18, 1991, págs. 375-410; Transitividad y complementación preposicional en español, Santiago, Verba, anexo 40, Universidade de Santiago de Compostela, 1995; Victoria Vázquez Rozas, El complemento indirecto en español, Santiago, Universidade de Santiago de Compostela, Colección Lalia, Series Maior, I, 1995.

${ }_{14}$ Vázquez Rozas, El complemento indirecto, loc. cit; Salvador Gutiérrez Ordónez, «Los dativos», Gramática descriptiva, loc. cit,, tomo II, Bosque, Demonte (eds.), págs. 855-1930.

15 Rafael Lapesa, «Los casos latinos: restos sintácticos y sustitutos en español», BRAE 44, 1964, págs. 57-105; Lapesa, «Sobre los orígenes», loc. cit.; Marcos Marín, Estudios, loc. cit.; Echenique, «El sistema referencial», l $\propto$ c. cit.; Carlos Folgar, Diacronia de los objetos directo $e$ indirecto (del latín al castellano medieval), Santiago, Verba, anexo 37, Universidade de Santiago de Compostela, 1993. 
2." Lo mismo sucede en el subconjunto de casos de clíticos en función de OD en estructuras triactanciales, que se realiza categóricamente mediante formas etimológicas en acusativo (A).

3. En las estructuras biactanciales los clíticos en función de oD tienen una moderada tendencia al uso de formas de dativo (D) siempre y cuando el antecedente sea de persona. Esta tendencia está condicionada por la existencia de vacilaciones históricas en el uso de los clíticos que sugiere una variación de interpretaciones ligada a las diferencias externas (normas dialectales) o internas (construcciones, significado, aspecto de los verbos, etc.). El criterio etimológico contribuye significativamente a la separación en dos subconjuntos: los casos con vacilaciones $\mathrm{A} / \mathrm{D}$ ya en latín y los casos con uso consistente $\mathrm{A}$. En el primer caso no tenemos prácticamente variación en el texto objeto de estudio, ya que el leísmo es casi categórico; en el segundo la variación es considerable.

4. La interacción de otros factores internos condicionantes del leísmo de persona, especialmente el género (masculino) y el número del antecedente (singular), delinea una situación conservadora del sistema etimológico similar a otras actuales, incluso en la lengua hablada. La situación que refleja el texto estudiado indica solo una continuidad más que notable de los usos latinos.

5. El análisis del condicionamiento interno lingüístico de la variación en el subconjunto de casos que se construían con $\mathrm{A}$ en latín permite vislumbrar explicaciones plausibles para el desarrollo inicjal y para la situación actual del letsmo de persona en los sistemas pronominales etimológicos del español. El número, la posición del clítico, la construcción y el tiempo del verbo son los condicionamientos variables que se combinan para explicar buena parte de la variación.

\section{Variables independientes}

Los grupos de factores (GF) que hemos considerado oportuno introducir en el modelo hipotético previo para la predicción del proceso variable son, ademís de los referidos a los rasgos del antecedente (número, género, clasema), la función del clítico y el tipo de referencia (anáfora o catáfora), la concordancia o discordancia entre el clítico y el antecedente, el clasema del sujeto de la oración, la posición del clítico con respecto al verbo, la duplicación de complementos (los reconoció a ellos, a ella la castigaron) y el tipo de construcción. A ellos se añaden el aspecto (desinente o permanente), el modo y tiempo del verbo, así como la presencia o ausencia de perífrasis modales y aspectuales y el uso canónico latino (A/D o A).

La necesidad de atenemos a una extensión predeterminada y razonable para esta primera versión de nuestro trabajo hace que concentremos en lo que 
sigue nuestra atención en aquellos grupos de factores que han resultado significativos en el análisis. En consecuencia, dejamos de lado observaciones de interés --algunas de carácter cualitativo, otras cuantitativas- sobre la influencia de factores internos cuya importancia habremos de tomar en consideración en futuras versiones.

La composición interna de los GF con efecto significativo en la variable dependiente estudiada aquí se expone con mayor detenimiento en el Cuadro 1 (\$ III.3.2).

\section{ANÁLISIS}

\section{Restricciones en el uso de las variantes: letsmo de persona}

En una primera aproximación a los datos de la Relación de los Hechos se pudo comprobar la naturaleza de las restricciones subrayadas arriba. De acuerdo con estos criterios, el uso pronominal que consta en la Crónica es el que aparece reflejado en la Tabla 1.

\section{TABLA 1}

Porcentajes de uso de los pronombres personales átonos en la Relación de los Hechos

\begin{tabular}{|c|c|c|c|c|c|c|c|}
\hline \multirow[b]{2}{*}{ PRON } & \multicolumn{2}{|c|}{$O D$} & \multicolumn{2}{|c|}{ OIND } & \multicolumn{2}{|c|}{ ATR } & \multirow[t]{2}{*}{ TOTAL } \\
\hline & $\mathbf{N}$ & $\%$ & $\mathrm{~N}$ & $\%$ & $\mathbf{N}$ & $\%$ & \\
\hline $\mathbf{L E}$ & 156 & 727 & 618 & 0.80 & 0 & 0.00 & 774 \\
\hline LO & 571 & 0.99 & 0 & 00 & 4 & 0.01 & 575 \\
\hline LA & 147 & 1.00 & 0 & 0.00 & 0 & 0.00 & 147 \\
\hline LES & 57 & (1.). & 269 & 0.83 & 0 & 0.00 & 326 \\
\hline Los & 216 & 1.00 & 0 & DEO & 0 & 0.00 & 216 \\
\hline LAS & 56 & 1.00 & 0 & 0.00 & 0 & 0.00 & 56 \\
\hline TOTAL & 1203 & 0.57 & 887 & 0.42 & 4 & 0.01 & 2094 \\
\hline
\end{tabular}

La observación de la mencionada tabla muestra que, en lo que respecta a la función, la única variación que se presenta es la alternancia LE, LES / LO, LOS, LA, LAS para la función OD ( 0.20 y 0.17 , respectivamente, para $\mathrm{LE} / \mathrm{s})$. Lo normal, pues, es que OD se formalice mediante LO/S, LA/S. Por otro lado, las formas de $\mathrm{A}(l o / s, l a / s)$ son exclusivas como expresión de $\mathrm{OD}$, con la excepción de los cuatro casos de función atributiva. Se comprueba, por lo tanto, la ten- 
dencia a la invasión de la función OD por LE/S (la inversa es inexistente, puesto que el $100 \%$ de los ONND se realiza mediante los canónicos LE/s) ${ }^{16}$.

16 Ejemplos

1) Atributo:

1. porque otros que non fuesen cavalleros cobdiçiasen de $h e$ ser (148r 30$)$

2) Objeto indirecto:

1. Troxieron un oso e echaronle los canes (89v 22)

2. Tomaron una cierva $[. .$.$] e quebráronle el braço (67v 13)$

3. El señor condestable fizo tomar algunas [liebres] bivas y echalles cascabeles (17r 7)

4. Los dichos regidores proveyeron de la dicha alcaldía al dicho Femando de Gormaz e diéronle la vara (41r 27)

5. Miércoles siguiente bolvieron a la señora doña Luisa a la iglesia mayor a le quitar el capillo (187v 14)

6. Todos los otros parientes e amigos e servidores del novio e de la novia diéronles michos presentes y bordones (305 14)

7. [las monjas] de cada día le rogavan por el acreçentamiento de la vida y estado del ser̂or condestable, que tari grande bien y limosna les avía fecho (301v 16)

8. Fue cosa que mucho quebrantó e de que en grand manera a los moros peso, diziendo que quatro días avía que estavan en salvo y que en fin d' ellos les quitaron la cavalgada (97v 25)

9. Commo fuese católico christiano e muy temerosos de Dios, e le pesase asaz d' esta guerra (204v 18)

10. A lo qual el señor condestable le respondió que le plazía mucho de su venida (309v 12)

Objeto directo:

1. el leonero tomó la leona y levóla a ençerrar do solía estar (23v 16)

2. en Jaén avía pocas bestias, porque las avian robado en la guerra (212r 22)

3. los cuales osos corrían fasta metellos por la cibdad (124r 31)

4. no pareçía sino que avíen entrado algund lugar de enemigos e $\underline{l}$ avían puesto a sacomano (40r 28)

5. fallóle en una barjoleta muchas cartas falsas (...) las cuales tomo, salvo una que paresḉá del señor rey, que $L a$ sacó del seno y se $h a$ comió (12v 31 )

6. fueron talados todos lo panes que por segar estavan [...] Y commo quiera que los moros $[\ldots]$ se esforçaron de $\underline{l o s}$ defender, non pudieron (325r 22)

7. commo fazen los çirugianos e físicos que curan las llagas cuando por melezinas blandas sanar non las pueden (192r 14)

8. acordó de se partir para allá. $\mathrm{Y}$ así lo fizo a veinte e seis días de enero del dicho año (16v 24)

9. [Gonçalo Mexia] llegó a fablar con su señoría en muy grande secreto y descubrióle commo estava ordenado de le matar a trayçión (263r 18)

10. mandava a sus guardas e cavalleros [...] que si algund mensagero viniese con carta 0 con fabla $(. .$.$) que le dixiesen que se bolviese, e si non lo quisiese fazer, que b$ matasen (201v 25)

11. ordenó su gente animándoles y poniéndoles muy grande esfuerço (195r 2)

12. do [...] se ayuntó toda la gente de la dicha çibdad. $\mathrm{Y}$ allí en las gradas les mandó leer çiertas cartas del rey nuestro seforor y les fablo muchas cosas por animallos y traellos al serviçio del dicho señor rey (225r 24)

13. el dicho señor condestable y la señora condesa tomaron la novia de braço, así cormmo quando $\underline{l a}$ levaron a misa (304r 15$)$

14. subió tuego a ver la señora condesa e a doña Guomar Carrillo [...] Y desque las ovo visto $[\ldots](142 \times 17)$. 
En la Tabla 2 se han incluido los resultados que interesan aquí; esto es, los usos de LE/LES en función de OD. Estos datos muestran una tendencia aún débil (0.18) al uso de LE / LES en función de OD en un sistema etimológico (LE/LES se usa mayoritariamente en el texto como OIND). Dicha tendencia es débil, lógicamente, con relación al total de casos en función de oD $(N=1203)$, donde se incluyen todos los clíticos del corpus con dicha funcion, sea cual sea la naturaleza semántica y referencial del antecedente.

TABLA 2

Porcentaje de uso le/les en función de $\mathrm{OD}$ en la Relación de los Hechos

\begin{tabular}{cccc}
\hline & TOTAL & LE, LES & LO, LOS, LA, LAS \\
\hline $\mathbf{N}$ & 1203 & 213 & 990 \\
$\%$ & 100 & 0.18 & 0.82 \\
\hline
\end{tabular}

Lo que interesa, en consecuencia, es considerar qué influencia tienen los rasgos del antecedente en esta variación. La variación pronominal en la función OD se da solo cuando el antecedente presenta el rasgo [+ persona], tal y como refleja la Tabla 3.

TABLA 3

Influencia de los rasgos del antecedente en el uso de los clíticos personales en función de OD en la Relación de los Hechos

\begin{tabular}{|c|c|c|c|c|c|c|c|c|c|c|}
\hline & \multicolumn{2}{|c|}{ PERSONA } & \multicolumn{2}{|c|}{ ANIMADO } & \multicolumn{2}{|c|}{$\cos A$} & \multicolumn{2}{|c|}{ NEUTRO } & \multicolumn{2}{|c|}{ TOTAL } \\
\hline & $\mathrm{N}$ & $\mathscr{\phi _ { 0 }}$ & $\mathbf{N}$ & $\%$ & $\mathrm{~N}$ & $\%$ & $\mathbf{N}$ & $\%$ & $\mathbf{N}$ & \% \\
\hline$L E$ & 156 & 028 & 0 & 0.00 & 0 & 0.00 & 0 & 0.00 & 156 & 0.13 \\
\hline Lo & 142 & 0.26 & 0 & 0.00 & 110 & 0.36 & 319 & 1.00 & 571 & 0.47 \\
\hline LA & 33 & 0.06 & 5 & 0.20 & 109 & 0.36 & 0 & 0.00 & 147 & 0.12 \\
\hline LES & 37 & 0.10 & 0 & 0.00 & 0 & 0.00 & 0 & 0.00 & 57 & 0.05 \\
\hline Los & 161 & 0,29 & 17 & 0.68 & 38 & 0.12 & 0 & 0.00 & 216 & 0.18 \\
\hline LAS & 3 & 0.00 & 3 & 0.12 & 50 & 0.16 & 0 & 0.00 & 56 & 0.05 \\
\hline TOTAL & 552 & & 25 & & 307 & & 319 & & 1203 & \\
\hline
\end{tabular}

En la Tabla 4 se han recodificado los resultados neutralizando las distinciones numéricas y genéricas, $\mathrm{y}$ distinguiendo únicamente entre antecedente personal y no personal. El uso de LE/S se produce tan solo en el caso de antecedente personal, como hemos dicho, si bien - como era de esperar- tal uso supone solo el $39 \%$ del total de casos con antecedente de persona para el ${ }^{2}{ }^{n}$.

${ }^{17}$ Como se vio arriba, el porcentaje sobre el número de casos de $\mathrm{OD}(\mathrm{N}=1203)$ es de 0.18 . Un caso especial es el de los antecedentes con el clasema [+ continuo]. Como era de esperar, la 
TABLA 4

Influencia del rasgo [ $\alpha$ persona] del antecedente en el uso de los clíticos personales en función de OD en la Relacion de los Hechos

\begin{tabular}{crcccc}
\hline \multirow{2}{*}{ ANTECEDENTE } & \multicolumn{2}{c}{ LE/S } & \multicolumn{2}{c}{ LO/S, LA/S } & TOTAL \\
\hline & $\mathrm{N}$ & $\%$ & $\mathrm{~N}$ & $\%$ & $\mathrm{~N}$ \\
PERSONA & 213 & $0 \% 39$ & 339 & 0.61 & 552 \\
No PERSONA & 0 & 0.00 & 651 & 1.00 & 651 \\
TOTAL & 213 & 0.18 & 990 & 0.82 & 1203 \\
\hline
\end{tabular}

\section{Variación de los cliticos con antecedente personal}

\subsection{El efecto del número y el género}

De la observación de los porcentajes de uso de los clíticos personales en la función de oD con antecedente personal (Tabla 5) se deriva la tendencia ya comentada al uso de las formas etimológicas de dativo le/es. Dicha tendencia alcanza 0.41 cuando el antecedente personal es masculino; es moderada (0.27) en plural, pero resulta predominante en singular (0.51). Casi irrelevante es el uso de le por $l e{ }^{18}$. Cuando el antecedente es femenino predominan las formas de acusativo (0.89) sobre las de dativo (0.14). Los datos indican que en plural el uso de las formas de dativo presenta un porcentaje más alto $(0.40)$ que en el singular (0.09), si bien tan acusado contraste se debe indudablemente al número reducido de casos.

variación que nos interesa se produce con antecedentes no continuos. Con antecedentes continuos únicamente aparece un caso de leismo en plural. Así pues, el uso pronominal responde también a la distinción de caso o función cuando el antecedente es un sustantivo continuo; del mismo modo, la variación pronominal responde a hechos de concordancia: cuando el antecedente es gente solo en 6 casos se da la concordancia formal $(25 \%)$ frente a 21 casos $(75 \%)$ de concordancia ad sensum; en cambio, con los continuos [ animado] solo en un caso se da la concordancia ad sensum $(8.33 \%$ frente al $91.67 \%$ ). Si distinguimos los casos con antecedente no animado de los personales, vemos que el uso de los pronombres átonos de tercera persona en la Crónica atiende a la función y sólo en el supuesto de que el antecedente sea [+ persona] presenta variación pronorninal en la función oD.

${ }_{18}$ [E] rey] le mandó delibrar a él y a todos los otros que con él detenidos estavar (14r 23). Sobre el uso de le por les en castellano medieval, véase Folgar, Diacronía, loc. cit., págs. 142148 y bibliografía alli citada). Otros ejemplos de le por les, pero en función de oIND, son: [...] dos cuentos qu' el rey nuestro señor le dio de renta a él e a sus hermanos (84r 2); algunos d'ellos preguntaron qué cabaliero, qué capitán era aqueí que allí venía. E algunos cristianos le respondieron qu'el condestable de Castilla (57v 29). 
TABLA 5

Variación genérica y numérica en el leísmo de persona en la Relación de los Hechos $(\mathrm{N}=552)$

\begin{tabular}{crccccr}
\hline & \multicolumn{2}{c}{ MASCULINO } & TơtAL & & FEMENINO & TOTAL \\
NÚMERO & & & & & & \\
\hline & $\mathrm{N}$ & $\%$ & $\mathrm{~N}$ & $\mathrm{~N}$ & $\%$ & $\mathrm{~N}$ \\
SING & 156 & 0.51 & 303 & 3 & 0.09 & 32 \\
PLU & 57 & 0.27 & 212 & 2 & 0.40 & 5 \\
& 207 & 0.41 & 515 & 5 & 0.14 & 37 \\
\hline
\end{tabular}

A partir de estos datos se puede inferir que el uso de $l e / s$ por $l o / s$ se establece, primero, con el rasgo [+ persona], en segundo lugar con el género (masculino) y, por último, con el número (singular).

\subsection{La influencia de la etimología}

El criterio etimológico, a saber, la interpretación funcional y causal de los clíticos en las construcciones latinas, constituye un factor muy importante -como se dijo arriba- en la predicción del leísmo de persona en nuestro texto. En la Tabla 6 se muestra la interacción de la influencia del caso y del número en el leismo de persona, una vez que se han eliminado los ejemplos femeninos ${ }^{19}$ que, como se vio, son prácticamente regulares en cuanto al mantenimiento de las formas etimológicas. El total de casos incluidos corresponde, como se recordará, a los clíticos cuya función sintáctica es de oD, habiéndose excluido todos los clíticos con función de oIND.

${ }^{15}$ El uso de LE/S referido a persona femenina ( 5 casos) se da con verbos cuya construcción latina presentaba alternancia A/D (ejemplos 1-3; cfr. Lapesa, «Sobre los orígenes», loc. cit., $\$ \$ 3-4)$ y con verbos de afección con sujeto inanimado (ejemplo 4; cfr. Vázquez, El complemento indirecto, loc. cit., págs. 211-212 y 227-235; Fernández-Ordónez, «Leísmo», loc. cit., páginas 1323-1325; Gutiérrez Ordóñez, «Los dativos», loc. cit., págs. 1879-1882), asf conю en un caso de concordancia ad sensum (ejemplo 5):

1. A la cual [novia] fallaron bien vestida e tocada [...] con muchas duesias y donzellas que le aconpañavan ( $305 \mathrm{r} 8$ ).

2. Do estava la señora condesa [...] y doña Guiomar $[$...] con muchas dueñas y donzellas de su casa y de la çibdad que les aconpañavan (170v 17).

3. Suplicaron [las monjas] al dicho señor condestable que en ello les quisiese ayudar, en tal manera que ellas fuesen reparadas (301, 18).

4. La señora doña Luisa se sintió mal de un açidente que los físicos llaman epilensia. E tan terrible fue e tan fuertemente le afincó, que dentro de tres o cuatro oras fallesçio (289r 12).

5. Puso muy grande recabdo en la dicha çibdad e ordenó su gente, animándoles y poniêndoles muy grande esfuerço (195r 2). 
TABLA 6

Interacción de la etimología y el número en el uso de los clíticos en función de OD en La Relación los Hechos $(\mathrm{N}=515)$

\begin{tabular}{|c|c|c|c|c|c|c|c|c|c|c|}
\hline \multirow{2}{*}{ CASO } & \multicolumn{2}{|c|}{ LE } & \multicolumn{2}{|c|}{ LO } & $\mathbf{N}$ & \multicolumn{2}{|c|}{ LES } & \multicolumn{2}{|c|}{ LOS } & $\mathbf{N}$ \\
\hline & 46 & 689 & 1 & 0.02 & 47 & 26 & 088 & 4 & 0.13 & 30 \\
\hline A & 110 & 48 & 146 & 0.57 & 256 & 31 & 0,17 & 151 & 0.83 & 182 \\
\hline TOTAL & 156 & Cs: & 147 & 0.49 & 303 & 57 & 0.23 & 155 & 0.73 & 212 \\
\hline
\end{tabular}

$\chi^{2}$ is A/D: 3.787. Sig. .072; A: 32.780. Sig. .000

$\chi^{2}=$ Sing: 47.923. Sig. .000; Plu: 63.527. Sig. .000

Las diferencias son significativas en tres de las cuatro combinaciones consideradas, de modo que, por ló que aquí interesa: $\left.1 .^{\circ}\right)$ las diferencias $(0.43 \mathrm{y}$ 0.17) en el uso de LE/S en los casos que en latín se construían en A en función del número (sing o plu) no se deben al azar; $2 .^{\circ}$ ) las mismas diferencias en función del número en los casos que en latín alternaban en $A / D$, sin embargo, si bien existen ( 0.98 y 0.87), pueden deberse a meras fluctuaciones estadísticas y, desde luego, no queda probado que respondan a la distinción morfológica de número; $3 .^{\circ}$ ) tanto en los clíticos personales en singular como en plural, las diferencias debidas a la etimología (0.98 y 0.43 en sing y 0.87 frente a 0.17 en plu) son significativas; es decir, es probable que la mayor frecuencia de LE/S en los clíticos que alternan $A D$ en latín se deba precisamente a su inclusión en ese grupo y no en el grupo de los clíticos con A regular en latín.

Así pues, queda comprobado que en el corpus de datos estudiado el lefsmo de persona es más frecuente en los ejemplos de clíticos masculinos en singular (0.51) que en plural (0.27) y si su caso en latín vacilaba entre $A / D(0.94)$ que si era categoricamente A (0.32). Esto quiere decir, como muestra la Figura 1 , a continuación, que el condicionamiento combinado de estos dos factores explica un porcentaje notable de la variación de los clíticos en el documento estudiado. Por un lado, la diferencia etimologica es muy importante; por otro, la diferencia numérica es significativa en los clíticos cuyo origen latino es $\mathrm{A}$, pero los clíticos cuyo origen latino es $A / D$ son indiferentes a la influencia del número (infra, § III.4.3). Lo que conviene, en consecuencia, es el análisis del uso de LE/S en el subconjunto de casos $(\mathrm{N}=438)$ en los que el clítico se construía en acusativo (A) en latín. 
FIGURA 1

Interacción del caso etimológico y el número en la frecuencia de uso de LE/S en función de OD en La Relación de los Hechos

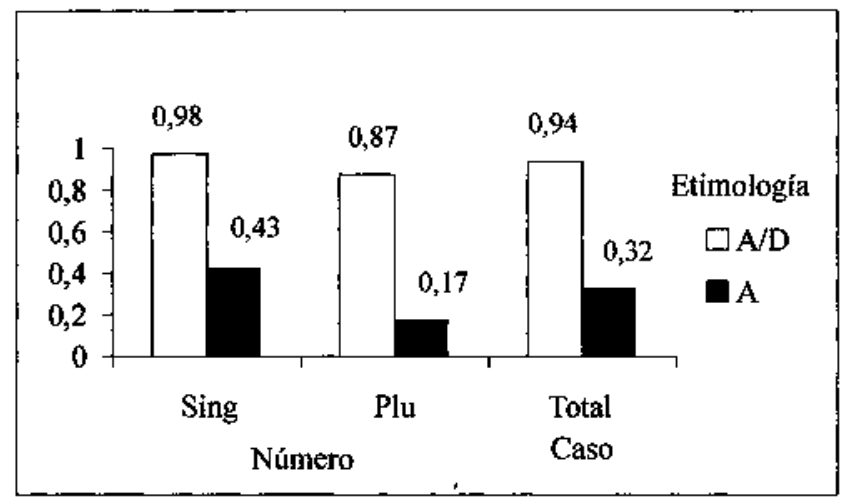

A: Acusativo en latín

A/D: Acusativo / Dativo en latín

\section{Condicionamiento lingüístico del uso variable de le/s}

\subsection{Análisis multivariable}

Ha quedado suficientemente probado que la selección variable de LE/S frente a $\mathrm{LO} / \mathrm{S}$ por parte del autor de nuestro documento resulta condicionada de manera previsible -y claramente observable en los datos generales- por factores léxicos (etimología) y gramaticales (género, número, persona). Sin embargo, en el subconjunto de casos (sing o plu) cuya atribución causal latina era acusativo (A) dicho condicionamiento no es tan evidente. Precisamos, por lo tanto, de un procedimiento que nos sirva para medir el efecto de las variables lingüísticas internas que hemos considerado como potencialmente condicionantes en dicho proceso de variación.

Como se argumentó arriba (§ II.1.2), partimos de la representación de la variación de LE/s como un proceso de elección (OD $\rightarrow\langle l e / s, l o / s\rangle$ ) y suponemos que la aparición de las variantes LE/S, LO/S depende del peso relativo de las variables independientes $(\$$ n.2.4), todas ellas internas. Se trata, pues, de un proceso que se adecua a los requisitos de un análisis multivariable que reúna las siguientes condiciones:

i) la variable dependiente tiene la forma de una variable nominal con altemativas, valores o variantes discretas;

ii) la elección no se puede predecir con seguridad a partir de la observación de la frecuencia de los valores o variantes de las variables independientes 
(factores contextuales); esto es así, al menos, en lo que se refiere al subconjunto de casos de OD en A;

iii) el proceso es frecuente, de modo que a partir de la observación de los patrones de uso en los datos, y de su relación con la frecuencia de las variables independientes o grupos de factores (GF) del entorno linguístico, es posible construir un modelo probabilístico que pueda servir para predecir usos en condiciones similares.

El análisis de regresión logística es el adecuado para la estructuración de los datos que hemos descrito. El modelo desarrollado por Sankoff y Rousseau ${ }^{20}$ conocido como VARBRUL (Variable Rule Analysis) ha sufrido diversas reformulaciones y aplicaciones informáticas hasta llegar a la versión que se utiliza aquí, que compara todos los modelos posibles de combinación de variables independientes o grupos de factores y elige, gracias a un algoritmo de selección (test de razón de verosimilitud), el que se ajusta mejor a los datos ${ }^{2 !}$. La versión del modelo de análisis variable (VARBRUL) que se emplea aquí ${ }^{22}$ es la adaptada para ordenadores McIntosh por Rand y Sankoff ${ }^{23}$ y conocida como Goldvarb 2.0.

Consideraremos primero ( $\$$ III.3.2 y III.3.3) el total de casos (A + A/D) y, a continuación, nos centraremos en el análisis específico del subconjunto A (§ III.4.1 y III.4.2). Por último, nos detendremos brevemente en el análisis separado de los casos en singular y plural (\$ III.4.3).

\subsection{La interacción de la etimología y los factores gramaticales}

Los GF que han resultado significativos en los sucesivos análisis multivariables se exponen en el Cuadro 1. Algunos grupos de factores pueden tener influencia en otros corpus diferentes, pero no en el que ha sido objeto de análisis por nuestra parte. Otros, aun siendo muy importantes —como el género o el clasema del antecedente- no pueden entrar en un análisis de este tipo, puesto que su efecto es categórico: de todo o nada. Así, por ej., se ha eliminado el subconjunto de casos en femenino dado su reducido número y, sobre todo, la escasa frecuencia de producción del leísmo de persona en los clíticos de dicho género. Un caso muy especial es el grupo 'animación del sujeto'. La relación

\footnotetext{
20 "Advances in variable rule methodology", loc. cit.

${ }^{21}$ Cfr. Sankoff, "Variable rules», loc. cit.; John C. Paolillo, Analyzing linguistic variation. Statistical models and methods, Leland Stanford, CSLI, 2001.

${ }^{22}$ Existe asimismo una versión más reciente (John Robinson, Helen Lawrence, Sali Tagliamonte, Goldvarb 2001. A multivariate anatysis application for Windows (October 2001), University of York, Dept. of Languages and Linguistics, 2001), conocida como Goldvarb 2001, que funciona en ordenadores PC compatibles bajo Windows.

${ }^{23}$ Goldvarb 2.0, loc. cit.
} 
entre el rasgo 'no animado' del sujeto y el uso etimológico es categórica, de modo que si el sujeto es no animado, el uso de $l e / s$ es predecible al $100 \%$, frente a cuando es animado, entorno en el que se emplea $l o / s$.

\section{CUADRO 1}

Grupos de Factores y Factores lingiústicos con efecto significativo en el leísmo de persona

\begin{tabular}{|c|c|c|}
\hline Grupos de Factores & & Factores \\
\hline 1 Etimología & A: Acusativo en latín & $\begin{array}{l}\text { A/D: Alternancia dativo / acusativo en } \\
\text { latín }\end{array}$ \\
\hline 2. Número & Sing: Singular & $\begin{array}{l}\text { Plu: Plural y otras diferentes } \\
\text { combinaciones referenciales de sing y plu }\end{array}$ \\
\hline $\begin{array}{l}\text { 3. Posición } \\
\text { 4. Tipo de } \\
\text { construcción }\end{array}$ & $\begin{array}{l}\text { Ant: Antepuesto al verbo } \\
\text { Vo: Verbo + OD }\end{array}$ & $\begin{array}{l}\text { Posp.: Pospuesto al verbo } \\
\text { VOxn: Verbo + OD + Cprep, Verbo + OD } \\
\text { + PTVO del OD, Sujeto de infinitivo }\end{array}$ \\
\hline 5. Tiempo & $\begin{array}{l}\text { NTp: Simultaneidad (presente, } \\
\text { imperfecto) y Formas no } \\
\text { Personales (infinitivo y } \\
\text { gerundio) }\end{array}$ & $\begin{array}{l}\text { Tp: Anterioridad (perfecto, tiempos } \\
\text { compuestos) y Posterioridad (fururo, } \\
\text { condicional) }\end{array}$ \\
\hline
\end{tabular}

Ejemplos:

1. Etimología

$A: \mathrm{Si}$ algund mensagero viniese con carta o con fabla [...] que le dixiesen que se bolviese, e si non lo quisiese fazer, que $\underline{l o}$ matasen (201v 25).

$A / D$ : commo el uno d'ellos [toro] tomase en los cuernos un onbre [...], con muy grand discriçión e presteza L $\underline{e}$ socorrió (36r 18).

2. Número

SING: el señor obispo $[\ldots]$ tantas vezes escrivió al señor condestable, que $\underline{l e}$ ovo de llevar a Cuenca (19r 21).

$P L U$ : ni los presos ni los que los levavan nin otro ninguno no sabían dó ivan $(49 \mathrm{v} 20)$.

3. Posición

$A N T$ : [Los cautivos cristianos] pensaron que si oviese quien les acorrer, que podrían tomar aquel castillo (72r 25).

POST: El dicho maestre y los suyos fuyeron. Pero luego vino a todo conrer una grand batalla del real en socorro e acorriéronlos (200r 14).

4. Tipo de construcción

$V O$ : se fizo justiçia d'ellos en esta manera: arrastráronles por todas las calles de la dicha çibdad [...] y enforcáronlos; y depués quartizáronlos e pusieron los cuartos en palos altos en el canpo (198r 8-12).

VOxn: don Pedro ovo de tomar e apoderarse del dicho castillo. Y commo entre otros que $\underline{e}$ ayudaron a ello [...] (282v 15).

Porque siempre $\underline{l} \underline{b}$ [antecedente: Pedro de Escavias] avía fallado firme y leal en el serviçio de su alteza (283v 14$)$.

Desque los prinçipales de la çibdad $\underline{\text { lo }}$ vieron partir con toda la cámara, preguntaron al camarero que dónde estava el señor condestable (18v 19).

Enbio a Sevilla por un buen maestro de gramática e mandóle asentar escuela en Ia çibdad de Jahén (316v 10). 


\section{Tiempo}

$N T p$ : Simultaneidad: Si esos cavalleros toman las parias [...] ¿por qué no los degiellas? $(54 \mathrm{v} 3)$.

Andava siempre con él [Fernando de Acuña] el comendador de Montizón [...] e otros cavalleros de su casa, que $\underline{l o}$ aguardavan e miravan por él (333r 19).

Formas no personales: pensando que los Abeçerrajes e los otros cavalleros que ende estavan saldrían tras ellos, e avría logar de los acochillar (98v 24).

Llarnaron los cristianos que subiesen por el escala, llamándolos perros traidores (75r 14).

$T p$ : Anterioridad: E después de salidos [los cristianos], açotáronlos muy cruelmente (75r 18).

Casi a toda el Andaluzía e a los cavalleros d'ella con sobornaçiones y dádivas [...] el dicho maestre de Calatrava los oviese atraf́do y convertido a seguir su opinión (191r 16).

Posterioridad: segund la parte en ella [Jaén] entendía fallar, que se apoderarian d'ella e non $\underline{Q}[$ [antecedente: el señor condestable] acogerían aunque viniese, $o$ si dentro estoviese, que $l o$ echarían fuera d'ella (85r 26).

El análisis multivariable confirma los resultados ya comentados (\$ III.1 y III.2) para el subconjunto de casos de oD con antecedente de persona con exclusión de los ejemplos femeninos $(\mathrm{N}=515)$. La probabilidad promediada de letsmo de persona, constante en todos los entornos en el subconjunto de casos considerado $(\mathrm{A}+\mathrm{A} / \mathrm{D})$, es notable $\left(P_{0}=0.410\right)$. Esto quiere decir que son de esperar más de cuatro casos de leísmo por cada diez clíticos en función de objeto directo con antecedente de persona.

En la Tabla 7a se muestran los resultados del análisis de regresión en el que se han excluido los casos femeninos por las razones ya aludidas. Cada columna corresponde a un modelo diferente; desde un modelo en el que no se considera el influjo de ninguna variable independiente, sino el promedio de todas ellas (Nivel 0), hasta la mejor combinación (Nivel 5), porque incluye todos los grupos de factores con efecto significativo $(p<0.050)$ sobre la variable dependiente. Se indica el logaritmo de verosimilitud para cada combinación de factores, la significación y el núm. de iteraciones necesarias para alcanzar la convergencia. Como se ha dicho antes, se incluye la $P$ input o probabilidad promedio $\left(P_{0}\right.$ en cada modelo, nivel o ecuación). En cada nivel se incluyen asimismo los grupos de factores seleccionados como significativos en la predicción. El último de cada columna es el incluido en dicho nivel.

El logaritmo de verosimilitud mide la bondad del ajuste a los datos de cada modelo, nivel o ecuación; la cantidad es siempre negativa y cuanto más se acerca a 0 mejor es el ajuste. Gracias a esta medida se van añadiendo, de nivel en nivel, los GF que suponen un incremento significativo de explicación de la variación con respecto al nivel anterior (el criterio de inclusión / exclusión es $p=0.050$ ). La convergencia entre los $G F$ se alcanza cuando no hay cambios significativos en dicha explicacion o estos son muy pequeños en las sucesivas 
combinaciones de los GF. La falta de convergencia puede indicar la existencia de interacciones de los grupos.

Para que la información sea accesible de modo completo, en la parte de abajo de la tabla se incluye el peso de los factores dentro del grupo introducido en cada nuevo nivel o modelo con la probabilidad que aquellos tienen en dicho nivel o combinación, si y solo si el peso es positivo (la contribución de cada factor es positiva si el peso del factor $>0.50$ y negativa si $<0.50$ ). Así, por ej., en el nivel 2, la categoría morfológica de número condiciona el proceso de selección de manera significativa (sig. 0.000 ), de tal modo que en singular dicha elección se produce con mayor frecuencia que en plural, tal y como indica la probabilidad de dicho factor (0.629). Los factores que condicionan negativamente la probabilidad de aparición de la variable dependiente $(p>0.50)$ se excluyen de la tabla.

El caso etimológico latino ('etimología') es el GF que más peso tiene en el leísmo de persona (Tabla 7a), en el sentido de que si el clítico considerado proviene de un étimo latino en el que hay altemancia $A / D$ la probabilidad es mucho más alta que la media $(0.50)$; esto es, prácticamente categórica $(p=0.939)$. La probabilidad constante cuando consideramos solo el GF 'etimología' es la más alta $\left(P_{0}=0.432\right)$. La combinaciôn de la etimología y el número (Nivel 2) produce un descenso leve de la probabilidad promedio $\left(P_{0}=0.422\right)$, cosa normal si tenemos en cuenta que desciende la frecuencia observada en los datos cuando los clíticos en A/D van en plural (supra, Figura 1). Como se observa en la Tabla 7a, dicha probabilidad constante sigue siendo superior a la $P_{0}$ inicial en los modelos 3 (en el que se introduce la variable 'posición') y 4 (que añade el GF 'tipo de construcción'), si bien al restringirse el número de entornos propicios para el leismo de persona (posición antepuesta al verbo y construcción 'no solo $O D$ ') desciende algo con respecto a la correspondiente al nivel 2. El siguiente modelo (5) introduce la variable 'Tiempo'.

$\mathrm{Al}$ introducirse el Tp, desciende la probabilidad general $(0.400)$, si bien la combinación y el peso particular del GF son significativos. Esto quiere decir que, en las condiciones especificadas antes en cuanto a la etimología (A/D), el número (sing), la posición (antepuesto) y el tipo de construcción ('VOxn'), si el tiempo del verbo indica 'simultaneidad' o 'no temporalidad' por tratarse de una forma no personal (infinitivo, gerundio), la probabilidad de la selección de $l e / s$ será de 0.593 . 


\section{TABLA 7a}

Influencia del entorno lingüístico en la probabilidad de leísmo de persona en La Relación de los Hechos. Análisis Varbrul de regresión logística binomial (método escalonado)

\begin{tabular}{|c|c|c|c|c|c|c|}
\hline Nivel & 0 & 1 & $\underline{2}$ & 3 & 4 & 5 \\
\hline $\mathbf{P}_{\mathbf{0}}$ & 0.410 & 0.432 & 0.422 & 0.415 & 0.411 & 0.400 \\
\hline Log. de Verosimil. & -348.539 & -295.510 & -277.737 & -267.952 & -260.760 & -250.007 \\
\hline Sig. & & 0.000 & 0.000 & 0.000 & 0.000 & 0.000 \\
\hline Convergencia & 2 & 6 & 6 & 6 & 7 & 7 \\
\hline Grupos de Factores & & Etimología & $\begin{array}{c}\text { Etimologia } \\
\text { Número }\end{array}$ & $\begin{array}{c}\text { Eximología } \\
\text { Número } \\
\text { Posición }\end{array}$ & $\begin{array}{c}\text { Etimología } \\
\text { Número } \\
\text { Posicjón } \\
\text { Construcción }\end{array}$ & $\begin{array}{c}\text { Etimología } \\
\text { Número } \\
\text { Posición } \\
\text { Construcción } \\
\text { Tiempo }\end{array}$ \\
\hline $\begin{array}{c}\text { Factores con efecto } \\
\text { positivo }\end{array}$ & & AdD 0.939 & $\begin{array}{ll}\text { AND } & 0.949 \\
\text { Sing } & 0.629\end{array}$ & $\begin{array}{r}\text { A/D } 0.948 \\
\text { Sing } 0.628 \\
\text { Ant. } 0.569\end{array}$ & $\begin{array}{ll}\text { A/D } & 0.953 \\
\text { Sing } & 0.626 \\
\text { Ant. } & 0.576 \\
\text { VOxn } & 0.676\end{array}$ & $\begin{array}{cc}\text { A/D } & 0.951 \\
\text { Sing } & 0.627 \\
\text { Ant. } & 0.584 \\
\text { Voxn } 0.704 \\
\text { NTp. } 0.593\end{array}$ \\
\hline
\end{tabular}

En la Tabla $7 \mathrm{~b}$ se muestra la contribución de los factores de cada GF a la aparición del leísmo de persona. Todos los grupos son bifactoriales. Los factores que favorecen el proceso estudiado son, por este orden jerárquico: la construcción etimológica en $\mathrm{A} / \mathrm{D}$, el núm. sing., la posición antepuesta del clítico, el tipo de construcción 'VOxn' y la simultaneidad de la acción expresada por el verbo o la falta de expresión de la temporalidad 'NTP'. Como se observa, se trata de la mejor combinación de factores (Nivel 5) del análisis representado en la Tabla $7 a$ (arriba).

\section{TABLA $7 b$}

Contribución de los factores significativos del entorno lingüístico a la aparición del leismo de persona en La Relación de los Hechos

\begin{tabular}{|c|c|c|c|c|}
\hline Etimología & Número & Posición & Construcción & Tiempo \\
\hline A/D 0.951 & Sing. 0.627 & Antep. 0.584 & VOxn 0.704 & NTp 0.593 \\
\hline ACUS 0.373 & Plu. 0.322 & Posp. 0.259 & vo 0.440 & $T_{p} \quad 0.326$ \\
\hline $\begin{array}{l}P_{0}=0.400 \\
\text { Log. Verosimilitud = } \\
\text { Sig. } 0.000\end{array}$ & -249.962 & & & \\
\hline
\end{tabular}




\section{Condicionamiento gramatical del leísmo de persona en acusativo}

\subsection{Interacción del número y los demás factores gramaticales}

Dada la frecuencia del uso de $l e / s$ referido a persona masculina con verbos que en latín se construían en dativo o alternaban con el acusativo (A/D), está claro que la variación en nuestro texto se limita prácticamente a los clíticos que en latín se construían regularmente en acusativo. Este hecho indica que hay un porcentaje de la variación estudiada que no depende del origen etimológico (esto es, de la interpretación causal latina del clítico), tal y como se ha comprobado antes, sino que cabe atribuirlo a la combinación de factores gramaticales del romance. Ahora bien, salvo error u omision, los patrones internos o gramaticales de variación descubiertos en el análisis anterior deberían permanecer inalterados, en el sentido de que en el subconjunto de clíticos con étimo acusativo funcionarán los mismos grupos de factores y con un efecto similar al observado en el total de los casos estudiado arriba. Las diferencias se reflejarán indudablemente (además, claro está, de la exclusión de los GF que no proceden) en la probabilidad de partida, puesto que la frecuencia del leísmo de persona es menor en los clíticos en caso etimológico acusativo (A) que en aquellos vacilantes en su origen latino entre el dativo y el acusativo (A/D).

En la Tabla 8a se muestran los resultados del análisis multivariable del subconjunto de casos $A(N=438)$.

TABLA 8a

Uso de LE/S en función de $O D$ con antecedente de persona y étimo en acusativo en La Relación de los Hechos. Análisis Varbrul de regresión logística binomial (método escalonado)

\begin{tabular}{|c|c|c|c|c|c|}
\hline Nivel & 0 & 1 & 2 & 3 & 4 \\
\hline $\mathrm{P}_{0}$ & 0.320 & 0.303 & 0.294 & 0.288 & 0.275 \\
\hline Log, de Verosimil. & -274.439 & -257.684 & -249.743 & -242.406 & -232.306 \\
\hline Sig. & & 0.000 & 0.000 & 0.000 & 0.000 \\
\hline Convergencia & 2 & 5 & 5 & 5 & 7 \\
\hline Grupos de Factores & & Número & $\begin{array}{l}\text { Número } \\
\text { Posición }\end{array}$ & $\begin{array}{l}\text { Número } \\
\text { Posición } \\
\text { Construcción }\end{array}$ & $\begin{array}{c}\text { Número } \\
\text { Posición } \\
\text { Construcción } \\
\text { Tiempo } \\
\end{array}$ \\
\hline $\begin{array}{c}\text { Factores con efecto } \\
\text { positivo }\end{array}$ & & Sing 0.630 & $\begin{array}{l}\text { Sing } 0.630 \\
\text { Ant. } 0.569\end{array}$ & $\begin{array}{l}\text { Sing } 0.628 \\
\text { Ant. } 0.576 \\
\text { VOxn } 0.678\end{array}$ & $\begin{array}{c}\text { Sing } 0.629 \\
\text { Ant. } 0.586 \\
\text { VOxn } 0.703 \\
\text { Ntp } 0.600\end{array}$ \\
\hline
\end{tabular}


Como se observa, los grupos y factores condicionantes son los mismos y en el mismo orden que en el análisis general (Tabla 7a). El efecto del número (sing) es el más importante (nivel 1); si tenemos en cuenta además la posición del clítico (antepuesto o pospuesto) y el tipo de construcción, las combinaciones son significativas en lo tocante al condicionamiento de la variable dependiente (niveles 2 y 3 ). Lo mismo ocurre con la introducción del GF 'tiempo' en el nivel 4; si se tiene en cuenta el 'tiempo' en la combinación, aumenta el efecto de los demás factores; a saber, cuando la construcción en la que aparece el clítico incluye una forma verbal que significa 'simultaneidad' (presente o imperfecto) o 'no temporalidad' (infinitivo o gerundio), ello supone un efecto significativo sobre el uso de $l e / s$. Este efecto es particularmente importante puesto que la diferencia de número interacciona con la distinción entre el tiempo simultáneo o la ausencia de tiempo frente al tiempo pasado o futuro (Figura 2).

Figura 2

Interacción del tiempo verbal y del número en los porcentajes de leismo de persona en acusativo (A) en La Relación de los Hechos

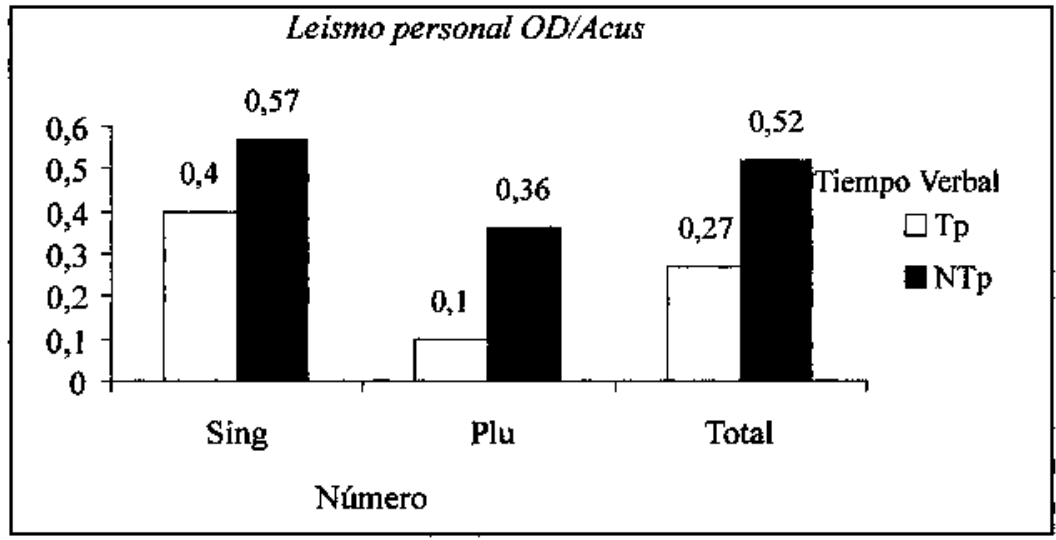

Singular: $\chi^{2}$, sig. .004

Plural: $\chi^{2}$, sig. .000

En la Tabla 8b, más abajo, se muestra la contribución de los factores sobre el leísmo de persona en A. Como puede comprobarse, al comparar estos resultados con los de la Tabla $7 \mathrm{~b}$, en la que se incluyeron los factores significativos en el leísmo de todos los clíticos (A/D + A), se observa que son los mismos, excepto el GF 'etimología' (que aquí no tiene sentido, al haberse seleccionado el conjunto de casos en A). 


\section{TABLA 8b}

Contribución de los factores significativos del entorno lingüístico a la aparición del leísmo de persona en oD y étimo en acusativo en La Relación de los Hechos

\begin{tabular}{llll}
\multicolumn{1}{c}{ Número } & Posición & Construcción & \multicolumn{1}{c}{ Tiempo } \\
\hline Sing. 0.629 & Antep. 0.586 & VOxn 0.703 & NTp 0.600 \\
Plu. 0.322 & Posp. 0.275 & VO 0.437 & Tp 0.333 \\
& & & \\
$P_{0}=0.275$ & & & \\
Log. Verosimil. $=$ & -232.306 & & \\
Sig. 0.000 & & & \\
\hline $\mathrm{N}=438$ & & &
\end{tabular}

Por otra parte, si consideramos el subconjunto de datos complementario, a saber, únicamente los casos con vacilación A/D y excluimos los ejemplos en A, los resultados son, como era de esperar, bastante distintos (Tabla 9).

TABLA 9

Contribución de los factores significativos del entorno lingüístico a la aparición del leismo de persona en OD y étimo en dativo A/D en La Relación de los Hechos

\begin{tabular}{cc} 
& Posición \\
\hline & \\
$P_{0}=0.941$ & Antep. 0.571 \\
Log. Veros. $=-18.358$ & Posp. 0.127 \\
Sig. 0.000 & \\
\hline $\mathrm{N}=77$ &
\end{tabular}

El único GF significativo es la posición del clítico; el resto de los grupos ffluye en la producción de un fenómeno prácticamente categórico en todos tornos.

den jerárquico de los efectos de las variables

unbinación de los grupos de factores gramaticales que interaccionan -un el número explica una parte considerable de la variación. En la Figura 3 se resume de manera gráfica la estructura del condicionamiento multifactorial sobre el leismo de persona en A. La figura representa idealmente el 'árbol de decisiones' que, tras el análisis probabilístico de la relación entre las frecuencias de $l e / s$ y los efectos de las variables gramaticales, suponemos que ha de seguir 
el hablante (en nuestro caso, el autor) al surgir un caso de uso virtual de clítico de persona en A. A la izquierda, tras la opción 'singular' se abren las selecciones 'posición antepuesta', 'VOxn' y 'no-tiempo'. A la derecha, quedan las opciones negativas o restrictivas del leísmo. Junto a cada opción se incluye la probabilidad correspondiente.

En la estructuración de la Figura 3 se representa asimismo (a la derecha de la línea vertical) la probabilidad constante en todos los entomos $\left(P_{0}\right)$ de leísmo personal en A. Como se puede observar, la constante $\boldsymbol{P}_{o}$ va cambiando conforme se van acumulando GF significativos a medida que se desciende en el árbol, hasta llegar al modelo de mejor ajuste, que incluye la acumulación de todos los grupos / decisiones. Así, se puede ver cuál es el efecto de la introducción de cada nueva variable en la probabilidad constante y cómo influyen las probabilidades de cada variable lingürstica independiente significativa en su efecto sobre la elección de le/s frente a lo/s (la referencia es la Tabla 8a, supra). En este sentido, la probabilidad de leísmo será más alta si el tiempo verbal no significa 'anterioridad' o 'posterioridad', si la construcción incluye más elementos que svo, si el clítico aparece delante del verbo y si el número del antecedente es singular.

\section{FIGURA 3}

Estructuración y orden jerárquico de los condicionamientos variables sobre el leismo personal en A en La Relación de los Hechos

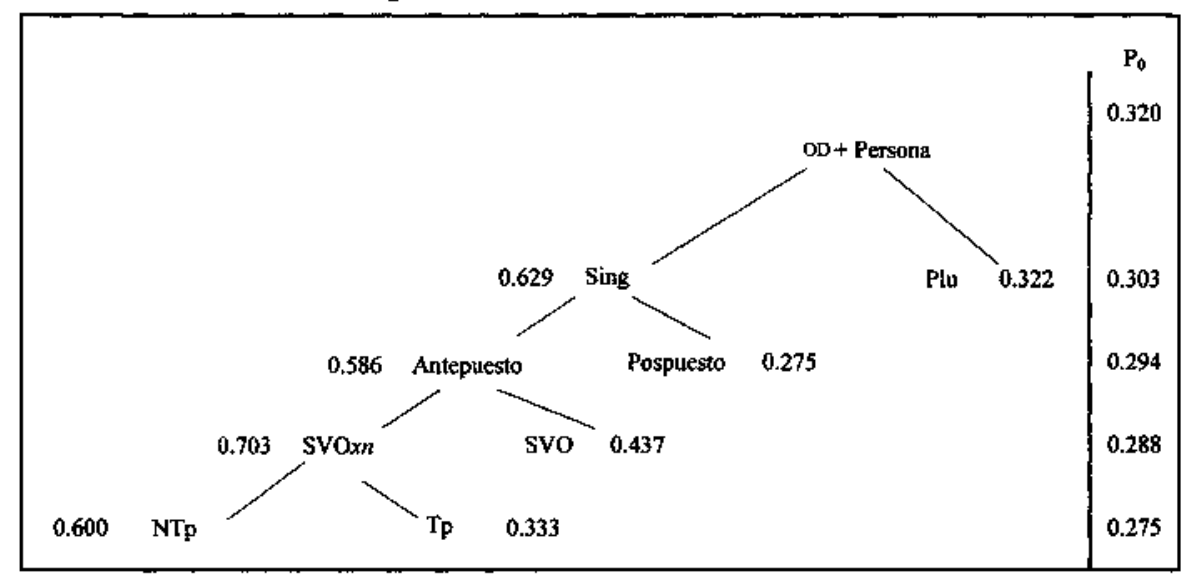

En resumen, como se ha podido observar, los resultados del análisis de la variación en los clíticos en función de $O D$ no son muy diferentes si consideramos: (1) todos los casos, ya fuesen en acusativo categóricamente en latín (A), ya vacilasen entre el acusativo y el dativo (A/D); (2) solo los casos que en latín se construían en acusativo (A), puesto que estos últimos son realmente los que 
presentan variación condicionada por el entorno gramatical y textual. Por el contrario, si se analizan solo los casos en D en latín, los resultados son casi categóricos y difieren de los dos anteriores, tanto en la $P_{0}$ como en los GF seleccionados.

La comparación explícita entre los resultados de los análisis del total (A/D) y del subconjunto de casos en acusativo etimológico (A) se muestra en la Figura 4.

\section{FIGURA 4}

Efecto de la etimología en la probabilidad constante $\left(P_{o}\right)$ de leísmo de persona en los modelos de regresión generales $(A / D+A)$

y de acusativo (A)

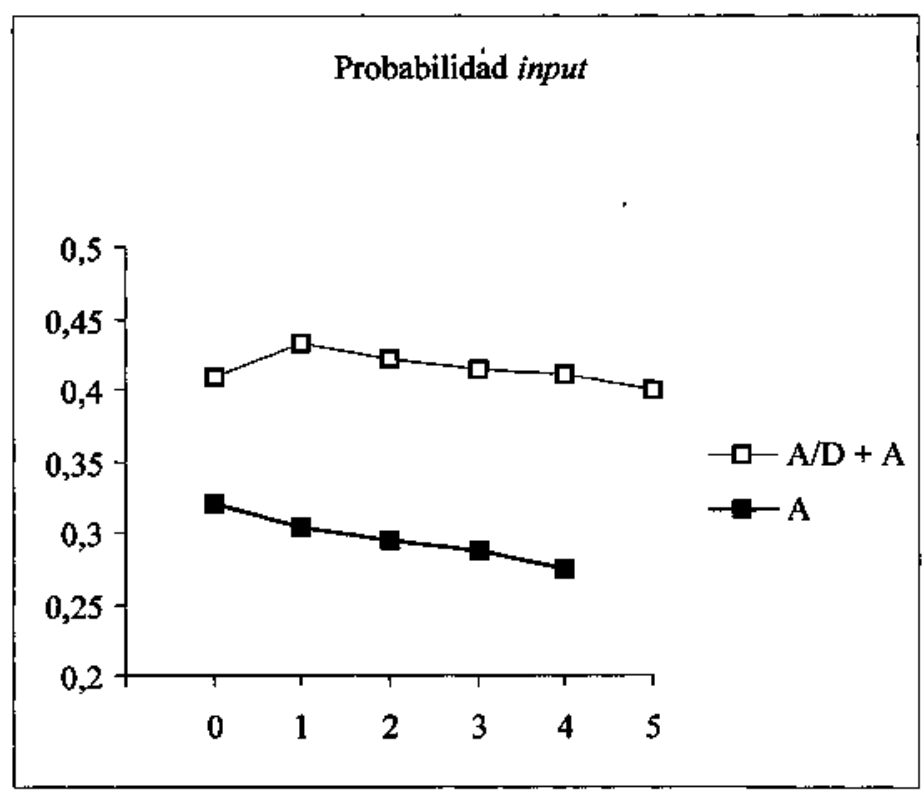

Como se observa, las probabilidades constantes de leísmo a través de todos los entomos $\left(P_{0}\right)$ son más altas en el conjunto mayor $(\mathrm{A} / \mathrm{D}+\mathrm{A})$, ya que los clíticos A/D se construyen con $l e / s$ de manera prácticamente categórica. Dicha diferencia de $P_{0}$ se mantiene constante en todos los niveles o combinaciones de GF en los análisis de regresión, con independencia de las variables independientes que se van acumulando en los sucesivos pasos (cfr., supra, Tablas 7a y 8a). 


\subsection{La variación en singular y en plural}

Dado el peso del número en la explicación de la variación de $l e / s$, parece conveniente establecer - de modo similar a lo efectuado con la etimología en los apartados anteriores- una comparación entre el leísmo personal en singur lar y plural. Para ello es necesario desarrollar dos análisis separados del leísmo de persona en ambas categorías morfologicas. Lo esperable, naturalmente, es que, por un lado, sigan teniendo efecto los mismos GF y en el mismo orden y, por otro, que sean sensiblemente diferentes las probabilidades constantes, tanto con respecto a los resultados de los análisis generales llevados a cabo hasta aquí, como entre sí, lo que reflejaría lo ya conocido: la mayor frecuencia esperada del leismo en singular.

En las Tablas 10 y 11, a continuación, se consideran los efectos interactivos del número y el caso etimológico sobre el letsmo de persona en el corpus de datos estudiado aquí. Se utilizan dos procedimientos distintos:

1) Por un lado, la partición del corpus general de ejemplos o tokens $(\mathrm{N}=515)$, que incluye los tokens en A y A D, tanto en singular como en plural, en cuatro subconjuntos: $1 .^{\circ} \mathrm{A} / \mathrm{D}+\mathrm{A}$ en singular; $2 .^{\circ} \mathrm{A} / \mathrm{D}+\mathrm{A}$ en plural; $3 .^{\circ} \mathrm{A}$ en singular; $4 .^{\circ} \mathrm{A}$ en plural (Tabla 10 ).

2) Por otro lado, la inclusión de un GF interactivo en el análisis del corpus general $(\mathrm{N}=515)$ que recoge las cuatro combinaciones anteriores (Tabla 11).

Al comparar los análisis de partición del corpus de tokens en la Tabla 10 se comprueba que el orden de los GF es el mismo en las sucesivas particiones, con la excepción del subconjunto de ejemplos en A plural, en el que el GF 'posición', hasta ahora incluido en todos los análisis, no tiene efecto significativo en el uso de les. Así mismo, el orden de los GF está alterado con respecto a los resultados del análisis general y del subconjunto de los casos en singular: el efecto de la variable 'tiempo' es más importante que el de la 'construcción'. Este hecho se explica con claridad cuando se observan los resultados del análisis interactivo que se desarrolla a continuación. 


\section{TABLA 10}

Influencia de los factores lingüísticos en diferentes subconjuntos de datos en función del número. Comparación de diferentes análisis VARBRUL del leísmo de persona en La Relación de los Hechos

\begin{tabular}{|c|c|c|c|c|}
\hline ANALISIS & PARTJCION & PARTKCIÓN & PARTFCION & PARTICION \\
\hline & SING $A / D+A$ & PLUAD + A & $\operatorname{SING} A$ & PLUA \\
\hline $\mathrm{P}_{\theta}$ & 0.502 & 0.207 & 0.411 & 0.134 \\
\hline Log. de Verosimil. & -185.524 & -83.696 & -157.019 & -74.241 \\
\hline Sig. & 0.016 & 0.046 & 0.005 & 0,036 \\
\hline Convergencia & 7 & 7 & 7 & 5 \\
\hline $\mathbf{N}$ & 303 & 212 & 256 & 182 \\
\hline \multirow[t]{4}{*}{ Grupos de Factores } & $\begin{array}{l}\text { Etimología } \\
\text { AD } 0.932 \\
\text { A } 0.384\end{array}$ & $\begin{array}{l}\text { Etimología } \\
\text { A/D } 0.955 \\
\text { A } 0.376\end{array}$ & & \\
\hline & $\begin{array}{l}\text { Posicion } \\
\text { Ant. } 0.530 \\
\text { Post. } 0.251\end{array}$ & $\begin{array}{l}\text { Posicion } \\
\text { Ant. } 0.564 \\
\text { Post. } 0.335\end{array}$ & $\begin{array}{c}\text { Posici6n } \\
\text { Ant. } 0.593 \\
\text { Post. } 0.240\end{array}$ & \\
\hline & $\begin{array}{l}\text { Construcción } \\
\text { VOxn } 0.703 \\
\text { VO } 0.429\end{array}$ & $\begin{array}{l}\text { Construcción } \\
\text { VOxn } 0.732 \\
\text { vo } 0.447\end{array}$ & $\begin{array}{l}\text { Construcción } \\
\text { VOxn } 0.700 \\
\text { Vo } 0.427\end{array}$ & $\begin{array}{c}\text { Tiempo } \\
\text { NTp } 0.672 \\
\text { Tp } 0.255\end{array}$ \\
\hline & $\begin{array}{c}\text { Tiempo } \\
\text { NTp } 0.590 \\
\text { Tp } 0.333\end{array}$ & $\begin{array}{c}\text { Tiempo } \\
\text { NTp } 0.652 \\
\text { Tp } 0.254\end{array}$ & $\begin{array}{l}\text { Tiempo } \\
\text { NTp } 0.574 \\
\text { Tp } 0.362\end{array}$ & $\begin{array}{l}\text { Construcción } \\
\text { VOxa } 0.697 \\
\text { VO } 0.452\end{array}$ \\
\hline
\end{tabular}

Por otra parte, se observa que la probabilidad de leismo en plural es sensiblemente inferior a la del singular en los cuatro subconjuntos considerados (Figura 5). Esto era de esperar dada la frecuencia observada y la relación entre ambas variables (supra \& III.2.2). De hecho, en el análisis general, como se constató (Tabla 7a), el efecto del singular era positivo (0.627), en tanto que el del plural era negativo (0.322). Paralelamente, se ha comprobado que el efecto del caso A era asimismo negativo (0.373), frente al efecto positivo (0.951) de A/D. Todo ello nos hace sospechar que el análisis interactivo puede ser intuitivamente más claro. 
FIGURA 5

Efectos de la interacción del caso etimológico y el número en la probabilidad promedio de leísmo de persona en La Relación de los Hechos

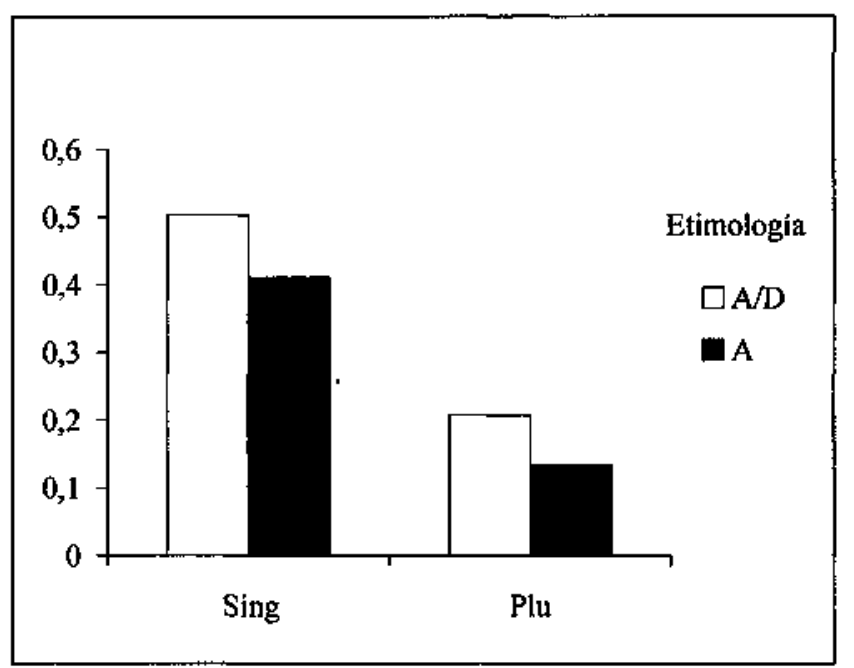

En la Tabla 11 se comparan los resultados del análisis general (cfr. Tabla 7a) con otros en los que se ha recodificado un GF interactivo que considera el efecto cruzado del peso de los GF más influyentes (el número y la etimología). Como se observa, en el análisis interactivo (columna tercera) se considera el efecto cruzado del caso etimológico y el número con las cuatro combinaciones posibles. El efecto del número tiene importancia crucial en el subconjunto $\mathrm{A}$, donde el plural tiene efecto negativo sobre el leísmo de persona $(0.220)$, en tanto que no influye prácticamente en el subconjunto A/D (en sing y plu el peso $>0.900$ ). Esta es la razón por la cual se realizó un segundo análisis interactivo (columna cuarta) con reducción del subconjunto A/D. La diferencia entre los tres análisis es pequeña en cuanto a la bondad del ajuste. 


\section{TABLA 11}

Comparación del análisis general y de los análisis interactivos (etimol. I núm.) del letsmo de persona en La Relación de los Hechos

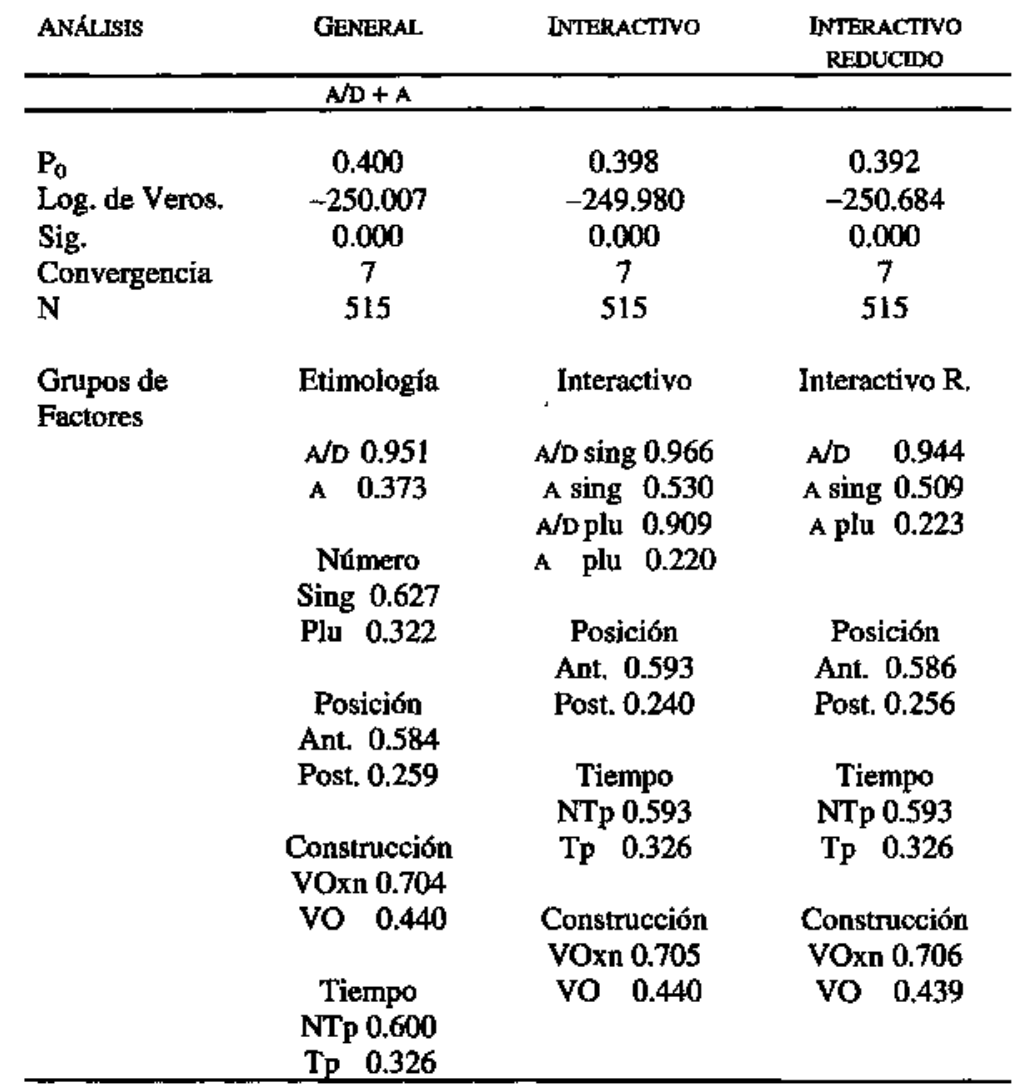

Los resultados son, en consecuencia, similares, puesto que el logaritmo de razón de verosimilitud varía muy poco. Sin embargo, el grupo interactivo de cuatro factores y, sobre todo, el reducido de tres capta con mayor simplicidad la naturaleza de la relación entre el caso y el número ${ }^{24}$. La Figura 6, por último, representa gráficamente la comparación de las probabilidades constantes de leísmo de persona en los cuatro entornos estudiados aquí.

\footnotetext{
${ }^{24}$ La alteración observable entre el análisis general ( $\left.\mathrm{A} / \mathrm{D}+\mathrm{A}\right)$ y los dos interactivos en lo que se refiere al efecto del tiempo y el tipo de construcción puede deberse a que el peso del tiempo es muy fuerte en la combinación A + plu.
} 


\section{FIGURA 6}

Contribución de los efectos interactivos del caso etimológico y el número en el leísmo de persona en la Relación de los Hechos

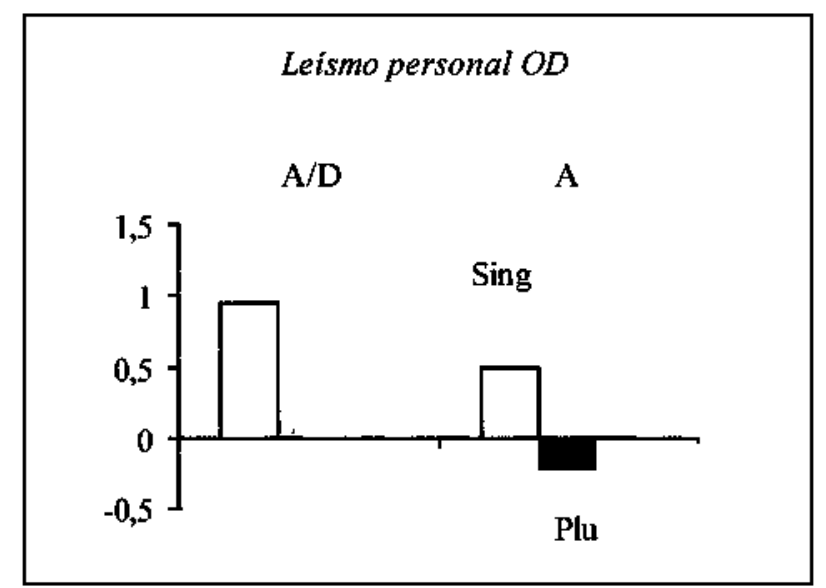

\section{CONCLUSIONES}

El estudio de los datos extrádos de La Relación de los Hechos permite corroborar algunas ideas previas sobre el origen del leismo en áreas de dominio del sistema etimológico, particularmente en la línea de una continuación indudable del uso latino, y sobre su limitación esencial al clasema 'persona'. El desarrollo de un análisis cuantitativo de los datos y, sobre todo, la utilización de técnicas multivariables ha permitido llegar a las siguientes conclusiones:

1. Existe una tendencia bastante fuerte a marcar con le (más que con les) el género masculino (de ahí que se excluya $l a / s$ prácticamente) no solo en la función de $\mathrm{OIND} / \mathrm{D}$ (donde tal uso es categórico) sino también en $\mathrm{OD}$.

2. En los clíticos en función de OD el leismo solo se da cuando el antecedente tiene el clasema 'persona'.

3. En dichas condiciones el factor etimológico es decisivo: el leísmo es prácticamente categorico si en latín el verbo se construía de manera vacilante A/D o si se construía abiertamente en $D$.

4. En los casos restantes, cuando el clítico se construía en latín en A sin vacilaciones, si bien se nota una tendencia a la extensión de $l e / s$, se puede decir que el cambio no está aún cumplido, de modo que es el ámbito que presenta mayor grado de variación. El uso del leísmo en estas condiciones depende de una estructura de condicionamientos lingüísticos cuyo funcionamiento, tal y 
como se puede observar en los resultados de los análisis de regresión logística desarrollados en el presente trabajo, es regular y constante. Las restricciones analíticas que se han efectuado aquí (análisis de todos los casos; solo de los casos en $\mathrm{A} / \mathrm{D}$; solo de los casos en $\mathrm{A}$; solo singular; solo singular en $\mathrm{A}$; solo plural; solo plural en A; análisis interactivos) demuestran que las modificaciones de los efectos de los grupos de factores sobre la variación de $l e / s$ son pequeñas y que lo que resulta modificada es la probabilidad inicial o general en cada subconjunto. Las diferencias entre los subconjuntos afectan siempre a la más importante interacción en los datos: caso etimológico / número y se manifiesta en la insensibilidad de los ejemplos en A/D al número y en el carácter restrictivo del leísmo asociado al número plural en el subconjunto A.

5. La mencionada estructura multivariable hace depender el leísmo de persona de la etimología, el número, la posición, el tipo de construcción y el tiempo del verbo, fundamentalmente. El fenómeno se produce por la tendencia a marcar el género y la persona y resulta condicionado por el número singular y por la incidencia de la construcción gramatical y de su interpretación, tanto en latín como en romance. 